\title{
PENGARUH BUDAYA ORGANISASI TERHADAP SEMANGAT KERJA PEGAWAI PADA DINAS KESEHATAN KABUPATEN PELALAWAN
}

\author{
Sudarmin Manik, Megawati \\ Sekolah Tinggi Ilmu Ekonomi Riau \\ e-mail: aminmanik82@gmail.com
}

\begin{abstract}
This research was conducted at the Pelalawan District Health Office. With the aim of research to determine the effect of organizational culture on the morale of employees at the Pelalawan District Health Office. The population in this study were all employees of the Pelalawan District Health Office, while the sample in this study were 83 employees. Analysis of the data used is validity test, reliability test, normality test, simple linear regression test and test coefficient of determination. While the hypothesis test uses the test. The results of this study that organizational culture variables have a positive and significant effect on employee morale at the Pelalawan District Health Office.
\end{abstract}

Keywords: Organizational Culture, Work Spirit

\begin{abstract}
Abstrak
Penelitian ini dilakukan pada dinas kesehatan kabupaten pelalawan. Dengan tujuan penelitian untuk mengetahui Pengaruh budaya organisasi terhadap semangat kerja pegawai pada dinas kesehatan kabupaten pelalawan. Populasi dalam penelitian ini adalah seluruh pegawai pada dinas kesehatan kabupaten pelalawan, sedangkan sampel dalam penelitian ini adalah sebanyak 83 pegawai. Analisis data yang digunakan adalah uji validitas, uji reliabilitas, Uji normalitas, uji regresi linear sederhana dan uji koefisien determinasi. Sedangkan uji hipotesis menggunakan uji t. Hasil penelitian ini bahwa variabel budaya organisasi berpengaruh positif dan signifikan terhadap semangat kerja pegawai pada dinas kesehatan kabupaten pelalawan.
\end{abstract}

Kata Kunci : Budaya Organisasi, Semangat Kerja

\section{PENDAHULUAN}

Birokrasi pemerintah yang merupakan organisasi yang semata-mata bekerja untuk memberikan pelayanan kepada masyarakat, yakni membantu menyiapkan atau mengurus apa-apa yang diperlukan oleh publik. Dengan kata lain pemerintah itu sebagai abdi masyarakat atau abdi negara yang melayani masyarakat.

Budaya organisasi merupakan salah satu peluang untuk membangun sumber daya manusia melalui aspek perubahan sikap dan perilaku yang diharapkan mampu menyesuaikan diri dengan tantangan yang sedang berjalan dan yang akan datang. Budaya organisasi merupakan suatu kekuatan sosial yang tidak tampak, yang dapat menggerakkan orang-orang dalam suatu organisasi untuk melakukan aktivitas kerja. Budaya organisasi yang kuat mendukung tujuan-tujuan perusahaan ataupun instansi pemerintahan.

Budaya organisasi memiliki peranan penting dalam mengelola suatu organisasi karena budaya organisasi merupakan persepsi yang sama tentang makna hakiki kehidupan bersama dalam organisasi. Kesamaan persepsi meliputi semua aspek kehidupan berorganisasi seperti hakekat tujuan dan berbagai sasaran yang ingin dicapai, strategi yang hendak diterapkan, visi dan misi organisasi, norma-norma berperilaku dalam organisasi, serta bentuk interaksi yang dikehendaki antara para anggota organisasi. 
Dinas kesehatan kabupaten Pelalawan adalah salah satu dinas pemerintahan daerah yang bergerak di bidang kesehatan masyarakat. Dengan adanya dinas kesehatan masyarakat dapat terjamin kesehatannya. Dengan demikian, dinas kesehatan haruslah memiliki tenaga kesehatan yang profesional, agar dapat memberikan pelayanan yang maksimal pada masyarakat. Berikut adalah jumlah pegawai dinas Kesehatan Kabupaten Pelalawan pada lima tahun terakhir.

Tabel 1 Data Jumlah Pegawai Dinas Kesehatan Kabupaten Pelalawan Tahun 2013-2017 Tahun Jumlah Pegawai Perkembangan

\begin{tabular}{lcc}
\hline 2013 & 128 & 0 \\
\hline 2014 & 129 & $0,78 \%$ \\
\hline 2015 & 126 & $-2,32 \%$ \\
\hline 2016 & 126 & $0 \%$ \\
\hline 2017 & 83 & $-34,13 \%$ \\
\hline
\end{tabular}

Sumber: Dinas Kesehatan Kabupaten Pelalawan 2018

Dari tabel 1 dapat dilihat bahwa pegawai pada Dinas Kesehatan Kabupaten Pelalawan mengalami fluktuatif setiap tahunnya. Hanya pada tahun 2016 pegawai tidak mengalami pengurangan ataupun penambahan. Tetapi tahun 2017 ada beberapa pegawai yang keluar dengan jumlah yang dratis. Sehingga dapat menutupi kekurangan pegawai pada dinas kesehatan kebupaten Pelalawan.

Budaya organisasi yang selalu dilakukan oleh seluruh pegawai Dinas Kesehatan Kabupaten Pelalawan adalah sebagai berikut:

1. Apel di kantor bupati setiap hari senin

2. Apel pagi dan apel sore dilakukan setiap selasa dan rabu

3. Senam kesegaran jasmani dilaksanakan setiap kamis pagi

4. Wirit bulanan dilakukan pada hari jum'at.

Dari kegiatan-kegiatan yang dilakukan pegawai setiap minggunya, masih ada beberapa pegawai yang tidak disiplin mengikuti kegiatan tersebut. Hal ini dapat disebabkan kurangnya semangat kerja pegawai pada dinas kesehatan kabupaten Pelalawan. Kegiatan-kegiatan yang sering di tidak diikuti pegawai adalah kegiatan apel pagi dan apel sore. Hai ini dikarenakan masih banyak pegawai yang terlambat dan pulang cepat.

Berikut adalah data kehadiran pegawai dinas kesehatan kabupaten Pelalawan dalam lima tahun terakhir.

Tabel 2. Absensi Pegawai Dinas Kesehatan Kabupaten Pelalawan 5 tahun terakhir

\begin{tabular}{cccccc}
\hline Tahun & $\begin{array}{c}\text { Jlh. } \\
\text { Pegawai }\end{array}$ & $\begin{array}{c}\text { Hari } \\
\text { Efektif/Thn }\end{array}$ & $\begin{array}{c}\text { Jlh Hari } \\
\text { Kerja/ } \\
\text { Thn }\end{array}$ & Alpa & $\begin{array}{c}\text { Persentase } \\
\text { Perkembangan }\end{array}$ \\
\hline 2013 & 128 & 235 & 36.736 & 190 & $26,67 \%$ \\
\hline 2014 & 129 & 287 & 30.960 & 204 & $7,37 \%$ \\
\hline 2015 & 126 & 240 & 29.610 & 280 & $37,25 \%$ \\
\hline 2016 & 126 & 235 & 29.610 & 340 & $21,42 \%$ \\
\hline 2017 & 83 & 235 & 19.505 & 322 & $-5,29 \%$ \\
\hline
\end{tabular}

Sumber: Dinas Kesehatan Kabupaten Pelalawan 2018

Dari tabel 2 dapat dilihat tingkat absensi pegawai dinas kesehatan kabupaten Pelalawan setiap tahun mengalami peningkatan. Hal ini dapat menyebabkan menurunnya kinerja pegawai tersebut. Tingkat 
absensi yang tinggi kemungkinan dapat disebabkan kurangnya gairah kerja pegawai pada dinas kesehatan kanbupaten Pelalawan. Untuk itu perlu dilakukan tindakan yang serius agar dapat meningkatkan kembali gairah kerja pegawai dinas kesehatan kabupaten Pelalawan yang menurun.

\section{METODE}

\subsection{Tempat Penelitian}

Penelitian ini dilakukan di dinas kesehatan Kabupaten Pelalawan yang beralamat di Komplek perkantoran Bhakti Praja Pangkalan Kerinci.

\subsection{Teknik Pengumpulan Data}

Dalam penelitian ini, penulis menggunakan cara pengumpulan data sebagai berikut :

a. Kuisioner. Kuisioner adalah daftar pertanyaan yang disebarkan kepada seluruh pegawai dinas kesehatan kabupaten Pelalawan. Untuk mengetahui pengaruh budaya organisasi terhadap semangat kerja pegawai digunakan skala likert. Skala likert digunakan untuk mengukur sikap, pendapat dan presepsi seseorang atau kelompok orang tentang fenomenal sosial. Dengan skala likert, maka variabel yang diukur dan dijabarkan menjadi indikator variabel. Jawaban setiap item yang menggunakan skala likert mempunyai gradiasi dan sangat positif sampai sangat negatif. (Sugiyono, 2010:107).

b. Wawancara. Wawancara adalah mengadakan wawancara langsung pada pegawai dinas kesehatan kabupaten Pelalawan tentang berbagai informasi/data, untuk bahan analisa yang diperlukan dalam penulisan penelitian ini.

\subsection{Analisis Data}

Uji Reliabilitas. Uji reliabilitas berguna untuk menetapkan apakah instrumen yang dalam hal ini kuesioner dapat digunakan lebih dan satu kali, paling tidak oleh responden yang sama akan menghasilkan data yang konsisten. Dengan kata lain, reliabilitas instrumen mencirikan tingkat konsistensi. Nilai koefisien reliabilitas yang baik adalah diatas 0,6 ( kuat), di atas 0,8 (sangat kuat). (Sugiyono, 2010:214).

\section{Uji Regresi Linear Sederhana}

Analisis regresi sederhana adalah analisis untuk mengukur besarnya pengaruh antara satu variabel independen dengan satu variabel dependen. Analisis ini digunakan untuk mengetahui arah hubungan antara variabel independen dengan variabel dependen apakah positif atau negatif dan untuk memprediksi nilai dari variabel dependen apabila nilai variabel independen mengalami kenaikan atau penurunan. Data yang digunakan biasanya berskala interval atau rasio. Rumus regresi linear sederhana menurut (Sugiyono, 2012:270) adalah sebagai berikut :

$$
\begin{aligned}
& \mathrm{Y}=\mathrm{a}+\mathrm{bX}+\varepsilon \\
& \text { Keterangan: } \\
& \mathrm{Y}=\text { Semangat Kerja. } \\
& \mathrm{a} \quad=\text { Konstanta } \\
& \mathrm{b} \quad=\text { Koefisien regresi } \\
& \mathrm{X} \quad=\text { Budaya Organisasi. } \\
& \varepsilon \quad=\text { Standar error }
\end{aligned}
$$

\section{Uji Koefisien Determinasi}

Analisis determinasi dalam regresi linear sederhana yang digunakan untuk mengetahui persentase sumbangan pengaruh variabel independen terhadap variabel dependen (Y). Koefisien ini menunjukkan seberapa besar persentase variasi variabel independen yang digunakan dalam model dan mampu 
menjelaskan variasi variabel dependen. $\mathrm{R}^{2}$ sama dengan 0, maka tidak ada sedikitpun persentase sumbangan pengaruh yang diberikan variabel independen terhadap variabel dependen atau variasi variabel independen yang digunakan dalam model tidak menjelaskan sedikitpun variasi variabel dependen. Sebaliknya $\mathrm{R}^{2}$ sama dengan 1 , maka persentase sumbangan pengaruh yang diberikan variabel independen terhadap variabel dependen adalah sempurna, atau variasi variabel independen yang digunakan dalam model menjelaskan $100 \%$ variasi variabel dependen.

Uji t

Digunakan untuk mengetahui pengaruh dan masing-masing variabel, baik variabel bebas terhadap variabel terikat yang signifikan secara statistik. Langkah-langkah pengujian uji t sebagai berikut : (Duwi Priyatno, 2008:57-58)

1. Menentukan Hipotesis

$\mathrm{H}_{0}$ : Tidak ada hubungan secara signifikan antara variabel independent dengan variabel dependent.

$\mathrm{H}_{\mathrm{a}}$ :Ada hubungan secara signifikan antara variabel independent dengan variabel dependent.

2. Menetukan tingkat signifikan. Pengujian menggunakan uji dua sisi dengan tingkat signifikan a $=5 \%$ (uji dilakukan 2 sisi karena untuk mengetahui ada atau tidaknya hubungan yang signifikan, jika 1 sisi digunakan untuk mengetahui hubungan lebih kecil atau lebih besar).

3. Menentukan t hitung

4. Menentukan $\mathrm{t}$ table. Tabel distribusi t dicari pada $\mathrm{a}=5 \%: 2=2,5 \%$ (uji 2 sisi) dengan derajat kebebasan $(\mathrm{df}) \mathrm{n}-2(\mathrm{df}=83-2=81$ yaitu sebesar 1,989$)$

5. Kriteria Pengujian. $\mathrm{H}_{\mathrm{o}}$ diterima jika $-\mathrm{T}$ Tabel $<\mathrm{T}$ hitung $<\mathrm{T}$ tabel

\section{HASIL DAN PEMBAHASAN}

\section{Uji Reliabilitas}

Uji reliabilitas digunakan untuk mengetahui konsistensi alat ukur, apakah alat pengukur yang digunakan dapat diandalkan dan tetap konsisten jika pengukuran tersebut diulang. Menurut Sekaran dalam Dwi Priyatno (2008:26), reliabilitas kurang dari 0,6 adalah kurang baik, sedangkan 0,7 dapat diterima dan di atas 0,8 adalah baik.

Berikut adalah hasil uji reliabilitas pada item pernyataan setiap Variabel.

\begin{tabular}{lll}
\multicolumn{3}{c}{ Tabel 3. Tabel Uji Reliabilitas Pada Setiap Variabel } \\
\hline No & Variabel & Cronbach's Alpha \\
& & \\
\hline 1 & Budaya Organisasi (X) & 0,864 \\
\hline 2 & Semangat Kerja (Y) & 0,919 \\
\hline Sumber: & Data Primer 2018 yang diolah
\end{tabular}

Dari tabel 5.34 dapat dilihat bahwa cronbach's alpha pada setiap Variabel X dan Y diatas 0,6, hal ini berarti reliabilitas baik (reliable).

\section{Uji Regresi Linear Sederhana}

Regresi linear berganda digunakan untuk mengetahui arah hubungan antara variabel independen terhadap variabel dependen. 
Tabel 4. Hasil Uji Regresi Linear Sederhana

\begin{tabular}{|c|c|c|c|c|c|}
\hline \multicolumn{6}{|c|}{ Coefficients $^{\mathrm{a}}$} \\
\hline \multirow[b]{2}{*}{ Model } & Unstandar & d Coefficients & $\begin{array}{c}\text { Standardized } \\
\text { Coefficients }\end{array}$ & \multirow[b]{2}{*}{$\mathrm{t}$} & \multirow[b]{2}{*}{ Sig. } \\
\hline & $\mathrm{B}$ & Std. Error & Beta & & \\
\hline $1 \quad$ (Constant) & 2,087 & 4,362 & &, 478 &, 634 \\
\hline Budaya Organisasi &, 815 &, 075 & ,770 & 10,862 & 000 \\
\hline
\end{tabular}

a. Dependent Variable: Semangat Kerja

Sumber: Data Primer yang Diolah 2018

Dari tabel 4 diatas dapat dilihat hasil regresi linear berganda yaitu: $Y=2,087+0,815 X$. Dari hasil data tersebut dapat dijelaskan sebagai berikut:

a. Konstanta sebesar 2,087 artinya jika budaya organisasi $(X)$ bernilai 0 , maka semangat kerja pegawai (Y) masih memiliki nilai sebesar 2,087.

b. Koefisien regresi Variabel budaya organisasi (X) sebesar 0,815, artinya jika budaya organisasi mengalami kenaikan 1 satuan, maka semangat kerja pegawai akan mengalami kenaikan sebesar 0,815 satuan.

\section{Uji Koefisien Determinasi}

\section{Tabel 5. Hasil Uji Koefisien Determinasi} Model Summary ${ }^{\mathrm{b}}$

a. Predictors: (Constant), Budaya Organisasi

b. Dependent Variable: Semangat Kerja

Sumber: Data primer 2018 yang diolah

Dari tabel 5 dapat dilihat bahwa nilai R 0,770. Hal ini berarti variabel budaya organisasi (X) memiliki hubungan yang erat terhadap semangat kerja pegawai dinas kesehatan Kabupaten Pelalawan. Sedangkan nilai adjusted $\mathrm{R}$ square sebesar 0,593, hal ini berarti variabel budaya organisasi (X) memberikan sumbangan pengaruh terhadap semangat kerja pegawai dinas kesehatan kabupaten pelalawan sebesar 59,3\% dan sisanya 40,7\% dipengaruhi oleh variabel lain yang tidak diteliti dalam penelitian ini.

Uji t

Tabel 6 Hasil Uji t

Coefficients $^{\text {a }}$

\begin{tabular}{|c|c|c|c|c|c|c|}
\hline \multirow{2}{*}{\multicolumn{2}{|c|}{ Model }} & \multicolumn{2}{|c|}{ Unstandardized Coefficients } & $\begin{array}{l}\text { Standardized } \\
\text { Coefficients }\end{array}$ & \multirow[b]{2}{*}{$\mathrm{t}$} & \multirow[b]{2}{*}{ Sig. } \\
\hline & & $\mathrm{B}$ & Std. Error & Beta & & \\
\hline \multirow[t]{2}{*}{1} & (Constant) & 2,087 & 4,362 & &, 478 &, 634 \\
\hline & Budaya Organisasi &, 815 &, 075 & ,770 & 10,862 & 000 \\
\hline
\end{tabular}

a. Dependent Variable: Semangat Kerja

Sumber: Data Primer yang Diolah 2018 
Dari tabel 6 dapat dilihat bahwa Variabel budaya organisasi (X) dengan $\mathrm{t}_{\text {hitung }}$ 10,862 dengan signifikan 0,000 lebih kecil dari 5\%. Maka $\mathrm{H}_{0}$ ditolak dan $\mathrm{H}_{\mathrm{a}}$ diterima. Artinya secara variabel budaya organisasi berpengaruh signifikan terhadap semangat kerja pegawai dinas kesehatan kabupaten pelalawan.

\section{KESIMPULAN}

Dari hasil penelitian yang telh dilakukan oleh penulis pada uraian sebelumnya mengenai Pengaruh Budaya Organisasi Terhadap Semangat Kerja Pegawai Dinas Kesehatan Kabupaten Pelalawan, maka dapat disimpulkan sebagai berikut:

a. Dilihat dari perhitungan uji-t, $t_{\text {hitung }}(10,862)$ lebih besar dari $t_{\text {tabel }}(1,989)$. Maka disimpulkan bahwa $\mathrm{H}_{\mathrm{a}}$ diterima dan $\mathrm{H}_{0}$ ditolak, jadi hipotesa yang menyatakan ada hubungan yang signifikan antara Budaya organisasi dengan Semangat Kerja Pegawai Pada Dinas Kesehatan Kabupaten Pelalawan dapat diterima.

b. Dilihat dari hasil regresi linear, bahwa $\mathrm{R}^{2}$ sebesar $59,30 \%$, sedangkan $40,70 \%$ dipengaruhi oleh faktor lain yang tidak diteliti dalam penelitian ini. Hal ini berarti budaya organisasi memiliki pengaruh terhadap semangat kerja pegawai Dinas Kesehatan Kabupaten Pelalawan.

\section{DAFTAR PUSTAKA}

[1].Achmad, Mansyur (2013). Dilema Desentralisasi \& Otonomi Daerah. Jatinangor: Alqaprint Jatinangor

[2].Agoes, Sukrisno dan I Cenik Ardana, 2009. Etika Bisnis dan Profesi Tentang Membangun Manusia Seutuhnya, Edisi Revisi, Salemba Empat, Jakarta.

[3].Andespa, Roni. 2012. Metodologi Riset Bisnis. Al-huda press. Pekanbaru.

[4].Arikunto, Suharsimi, 2010. Prosedur Penelitian, Edisi Revisi, Rineka Cipta, Jakarta.

[5].As'ad. Muhammad. 2003. Kepemimpinan Efektif Dalam Perusahaa. Ed. 2. Liberty. Yogyakarta.

[6]._ 2009. Seri Ilmu Sumber Daya Manusia: Psikologi Industri, Edisi IV. Yogyakarta: Liberty

[7].Ayu Maristiana. 2007. Analisis Pengaruh Motivasi Dan Penempatan Pegawai Terhadap Semangat Kerja Pada Dinas Tata Kota Bandar Lampung Jurnal Sains dan Inovasi III(2)123-130

[8].Fahmi, Irham. 2014. Perilaku Organisasi. Alfabeta. Bandung.

[9].Ghazali Imam, 2005. Analisis Multivarience Dengan Program SPSS, Universitas Diponegoro, Semarang.

[10].Hasibuan, S.P Melayu. 2012. Manajemen: Dasar, Pengertian, dan Masalah. Edisi Revisi. Jakarta : Bumi Aksara. 
[11].Jauhari, Slamet. 2015. Pengaruh Budaya Organisasi Terhadap Semangat Kerja Pegawai Bagian Umum Sekretariat Daerah Kabupaten Boyolali. Fakultas Ekonomi Universitas Surakarta. Jurnal Manajemen Sumber Daya Manusia Vol. 9 No. 2 Desember 2015: 181 - 188

[12].Manullang, M, 2009. Dasar-Dasar Manajemen, Cetakan ke XXI, Gadjah Mada University Press, Yogyakarta.

[13].Masngudi dan M. Noor Salim. 2012. Metodologi Penelitian untuk Ekonomi dan Bisnis. Trianandra University Press. Jakarta

[14].Marlinda, Pebriana. (2017). Analisis Perencanaan Kebutuhan Tenaga Dokter Oleh Dinas Kesehatan Kota Pekanbaru. Jurnal Niara, 9(2), 71-83. Https://Doi.Org/10.31849/Nia.V9i2.2100

[15]. Prihati, Prihati, \& Hernimawati, Hernimawati. (2016). Analisis Budaya Organisasi Pegawai Di Kantor Camat Rumbai Pesisir Kota Pekanbaru. Jurnal Niara, 9(1), 5-9. Https://Doi.Org/10.31849/Nia.V9i1.2011

[16]. Priyatno, Duwi, 2008. Mandiri Belajar SPSS (Statistical Product and Service Solution), MediaKom, Yogyakarta.

[17].Sedarmayanti, 2011. Manajemen Sumber Daya Manusia, Reformasi Birokrasi Dan Manajemen Pegawai Negeri Sipil, Cetakan ke V, PT. Refika Aditama, Bandung.

[18].Simamora, Henry, 2014. Manajemen Sumber Daya Manusia, STIE YKPN, Yogyakarta.

[19].Soetopo, Hendyat. 2010. Perilaku Organisasi. Rosda. Bandung.

[20].Sugiyono. 2010. Metode Penelitian Administrasi, Cetakan XVIII, Alfabeta, Bandung.

[21]. 2009.Metode Penelitian Bisnis, Bandung: cv. Alfabeta

[22].Sutrisno, Edy. 2015. Manajemen Sumber Daya Manusia, Kencana Prenada Media Group, Jakarta.

[23].Tika, Moh. Pabundu. 2010. Budaya Organisasi dan Peningkatan Kinerja Perusahaan. Bumi Aksara. Jakarta.

[24].Wibowo. 2010. Manajemen Kinerja. Edisi Ketiga. Rajawali Press. Jakartawo. 2012. Manajemen Kinerja, edisi keempat. Jakarta: Rajawali Press. 